\title{
A Dual-Polarized Printed Antenna Based on a Tapered Slot SICL Balun for Airborne Radar Application
}

\author{
Xiaochun Liu, ${ }^{1,2}$ Li Wang $\mathbb{D}^{3}{ }^{3}$ Mingxi Zhang, ${ }^{1,2}$ Shaobin Liu, ${ }^{2}$ and Guiqiang $\mathrm{Du}^{4,5}$ \\ ${ }^{1}$ College of Electronic and Information Engineering, Nanjing University of Aeronautics and Astronautics, Nanjing 211106, China \\ ${ }^{2}$ The Aeronautical Science Key Laboratory for High Performance Electromagnetic Windows, Jinan 250023, China \\ ${ }^{3}$ School of Information Science and Engineering, Harbin Institute of Technology at Weihai, Weihai 264209, China \\ ${ }^{4}$ School of Space Science and Physics, Shandong University, Weihai 264209, China \\ ${ }^{5}$ State Key Laboratory of Surface Physics and Department of Physics, Key Laboratory of Micro and \\ Nano-Photonic Structures (Ministry of Education), Fudan University, Shanghai 200433, China
}

Correspondence should be addressed to Li Wang; hitweihaiwangli@163.com

Received 1 May 2019; Revised 17 August 2019; Accepted 8 October 2019; Published 14 March 2020

Academic Editor: Giuseppina Monti

Copyright ( 2020 Xiaochun Liu et al. This is an open access article distributed under the Creative Commons Attribution License, which permits unrestricted use, distribution, and reproduction in any medium, provided the original work is properly cited.

The substrate-integrated coaxial line (SICL) is a potential transmission line due to its good characteristics of high efficiency, nondispersive, and single operational mode. A tapered slot SICL balun is proposed, which can realize the impedance transformation from the microstrip line to the coplanar strip line (CPS). At the same time, the proposed balun can transform the quasiTEM mode of the microstrip line to the TEM mode of CPS. A printed dipole radiator is designed and is fed by the proposed SICL balun to achieve the impedance matching. The dual-polarized radiation mode is realized by employing two orthogonal printed dipoles. For each polarization radiator, the CPS is bended to avoided the occlusion of two polarization ports and realize the direct assembling of two orthogonal printed circuits. What is more, the assembling method is advantageous to improve the port isolation degree and decrease the cross polarization level. To improve the ratio of front to back $(\mathrm{F} / \mathrm{B})$ of the radiation pattern, a cylindrical metal cavity is adopted. According to the results of simulation and experiments, the VSWR of each port is lower than 2, the isolation degree between two polarization ports is higher than $20 \mathrm{~dB}$, and the cross polarization level at the boresight is lower than $-20 \mathrm{~dB}$ at the operational frequency. The patterns of two ports are almost symmetric, and high radiation efficiency is obtained. The experimental results of the principle prototype verify the design schemes of the balun and the dual-polarized antenna. The proposed dual-polarized antenna fed by the tapered slot SICL balun is suitable for the airborne radar application.

\section{Introduction}

For the airborne radar, the dual-polarized system can achieve the remarkable improvement of operational performances. Especially, the polarization signal processing technique has huge application potential in the field of interference suppression. The dual-polarized antenna is the key component of novel airborne radar and has drawn more and more attention. So far, a lot of schemes of dual-polarized antennas have been proposed, which include dual-polarized microstrip antenna [1], dual-polarized dielectric resonator antenna [2], dual-polarized horn antenna [3], dual-polarized slot antenna [4], dual-polarized monopole antenna $[5,6]$, dual-polarized dipole antenna [7], and dual-polarized lens antenna [8]. Whereas, the dual-polarized dipole antenna is suitable for the airborne application in view of its characteristics of simple structure, low cost, and stable performance. For the design of the dual-polarized dipole antenna, balun is hard to research and design, which realize the conversion from the balanced port to the unbalanced port.

In 2006, the SICL was proposed, and it has a lot of advantages such as wideband, low loss, strong interference suppression ability, and convenient integration. SICL supports propagation of the transverse electromagnetic (TEM) mode wave, and hence, it is a nondispersive transmission line which can work within the frequency range from zero frequency to microwave band. Recently, SICL has obtained more attention in the microwave technical field. At present, 


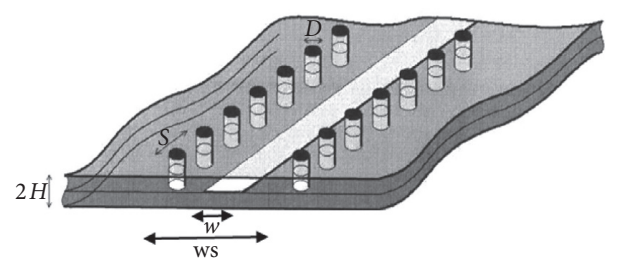

FIgURE 1: Structure diagram of the typical SICL.

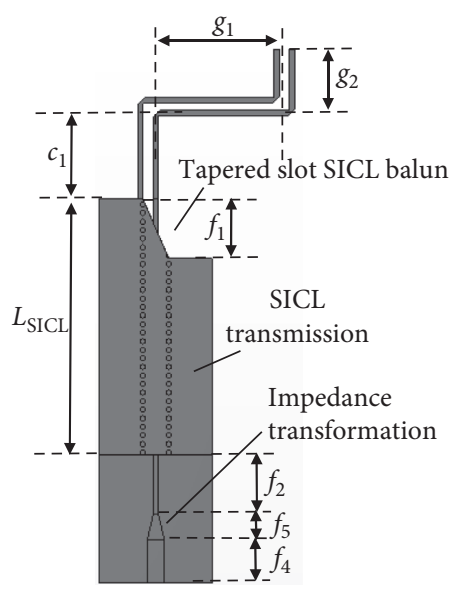

(a)

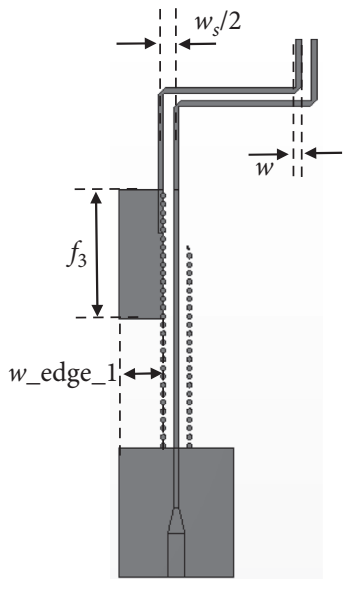

(b)

FIgURE 2: Structure diagram of the SICL balun. (a) The whole feeding structure. (b) The whole feeding structure when the grounds on the top and bottom of substrates are concealed.

the SICL can be used to design the antenna [9-14], balun [15], and transition between SICL [16, 17] and filter [18-20].

In [9], a multichannel SICL array with coaxial lines placed in both vertical and horizontal directions was proposed for high-speed parallel data transmission, and its maximum bandwidth of a single channel of the SICL array is up to $56 \mathrm{GHz}$, and the coupling of adjacent channels in the SICL array is less than $-30 \mathrm{~dB}$. In [10], a wideband circularly polarized cavity-backed patch antenna excited by SICL was proposed operating at Q-band for IEEE 802.11aj (45 GHz) applications. The growing interest in collision avoidance automotive radar systems in Ka-band necessitates the development of dedicated antenna systems with a $45^{\circ}$ inclined linear polarization (LP). A $45^{\circ}$ inclined and linearly polarized slot array antenna in the Ka-band with SICL technique is presented for collision avoidance automotive radar system application in [12]. Zhu et al. [15] proposed an ultrawideband (UWB) Marchand balun by using substrate-integrated coaxial line (SICL) technology, which is suitable for applications in UWB communication systems. A highquality transition from coplanar waveguide to empty coaxial line is proposed in [16]; with this transition, the coaxial line is completely integrated in a planar circuit board so that it truly becomes an empty substrate-integrated coaxial line. A transition from microstrip to empty substrate-integrated coaxial line (ESICL) is presented in [17].

In [18], a compact filter based on SICL stubs was designed using an advanced multilayer printed circuit board (PCB) substrate, and this technology is convenient to

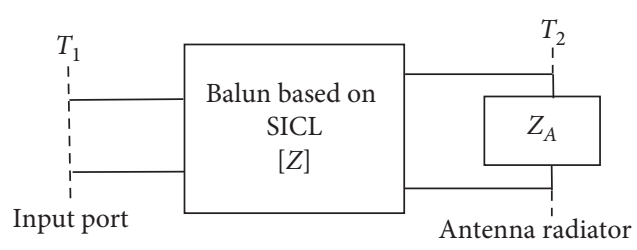

Figure 3: The circuit model of the SICL balun.

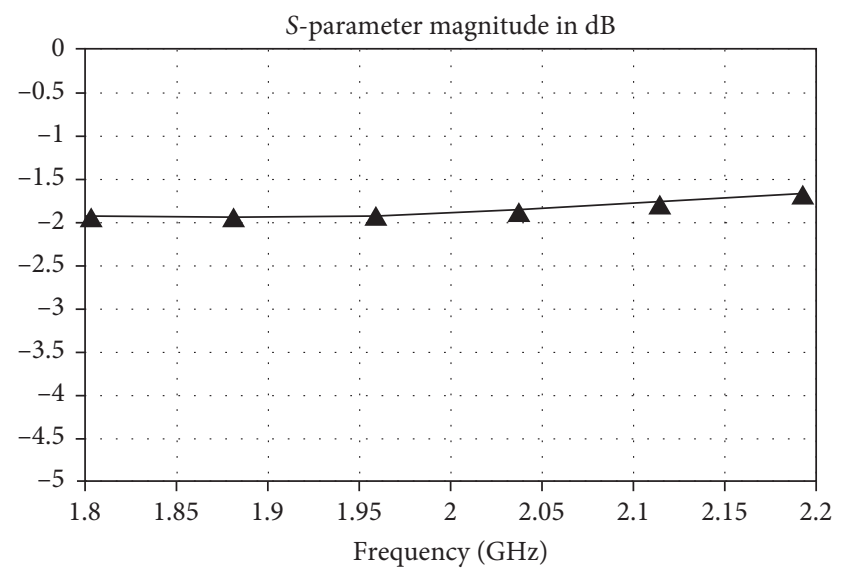

Figure 4: The simulated transmission performance curve of the designed balun.

implement high-density interconnect (HDI) devices, which are dedicated to mass market and require to be compact and low cost. Borja et al. [19] presented the design and 


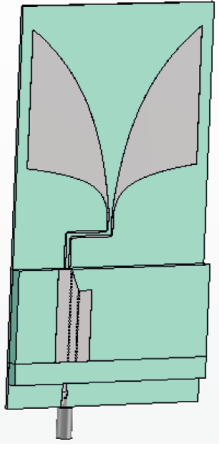

(a)

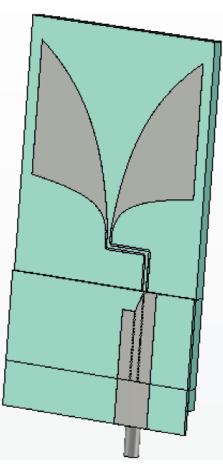

(b)

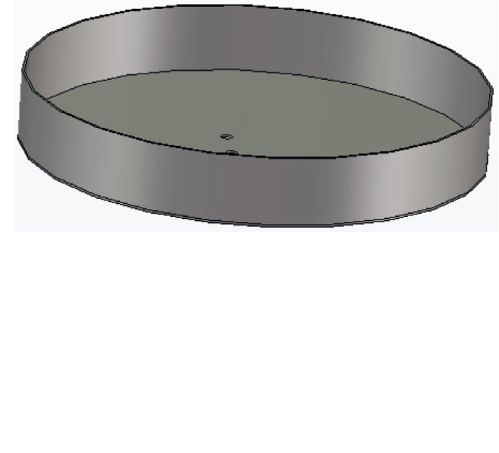

(c)

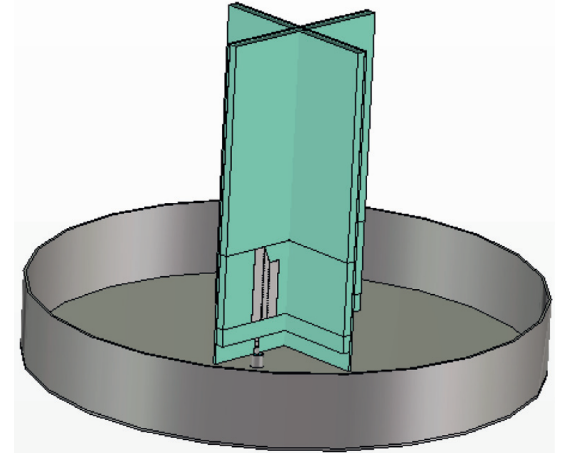

(d)

Figure 5: Schematic diagram of the dual-polarized antenna based on the SICL balun: (a, b) polarization port 1, (c) back cavity, and (d) structure of the whole dual-polarized antenna.

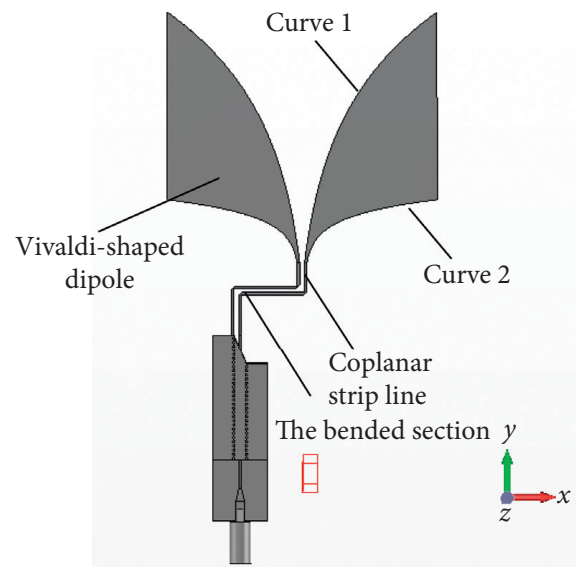

FIGURE 6: Structure diagram of the Vivaldi-shaped dipole antenna based on the SICL balun.

performance of a planar narrow bandwidth bandpass filter with high-quality factor, and its structure is composed of an empty substrate-integrated coaxial line with the center conductor suspended in air. A novel wide stopband bandpass filter implemented with spur stepped impedance resonator (SSIR) and SICL technology is proposed in [20]. A tapered slot balun based on SICL was proposed in this paper, and then a dual-polarized dipole antenna was designed by employing the proposed SICL balun for the airborne application. The geometry structures of the proposed SICL balun and dual-polarized antenna are presented in Section 2. The performance analysis and optimization of the dualpolarized antenna are carried out in Section 3. The experimental results of the antenna prototype are provided in Section 4, and conclusions are drawn in Section 4.

\section{Geometry Structure of the Tapered Slot SICL Balun and the Dual-Polarized Antenna}

2.1. SICL Structure. SICL is a kind of technology of the planarization of the coaxial line. Like the traditional coaxial cable, SICL is also a shielding and nondispersive TEM guiding wave structure, which has features of wideband, low loss, high $Q$, small size, and convenient connection with the high-speed system. The first high-order mode for SICL is $\mathrm{TE}_{10}$, and intermediate conductor does not affect the field characteristics of the $\mathrm{TE}_{10}$ mode. The single-mode bandwidth can be controlled by adjusting the spacing between two rows of metalized via holes, which can realize wider band than the substrate-integrated waveguide (SIW). SICL is mainly composed of the conductor in the bottom which is connected with the ground, intermediate conductor, and the conductor on the top, two side walls which consist of metalized holes and two substrate layers. Herein, the outside conductors are formed from the bottom conductor, two side walls, and top conductor. A typical SICL structure is shown in Figure 1. Under certain assumptions, the cutoff frequency of SICL for the $\mathrm{TE}_{10}$ mode can be expressed by

$$
f_{\mathrm{TE}_{10}}=\frac{c}{2 \sqrt{\varepsilon_{r}}}\left(\mathrm{ws}-\frac{D^{2}}{0.95 S}\right)
$$

where ws, $D$, and $S$ are shown in Figure 1, and $c$ is the light speed in vacuum. Because $D$ and $S$ are limited by the PCB manufacturing process, the cutoff frequency of the $\mathrm{TE}_{10}$ mode is the single-mode band of SICL.

2.2. Design of the Tapered Slot SICL Balun. Figure 2 shows the tapered slot SICL balun which is one of the dual-polarized dipole antenna ports, and these two ports have the same SICL balun. The whole feeding structure is composed of the tapered slot SICL balun, SICL transmission section, and impedance transformation section. The SICL balun is connected with the dipole radiator and SICL transmission section, herein the symmetric dipole excited by CPS is the balanced structure, and the SICL transmission line is the unbalanced structure. The length of the SICL transmission line was $L_{\mathrm{SICL}}-f_{1}$, and this section has advantages of single mode, nondispersive, and low signal loss. For the impedance transformation section, the microstrip line adopted linearly tapered form, in which length was $f_{5}$. The end section was a uniform microstrip line with a length of $f_{4}$, and its characteristic impedance was $50 \Omega$. The impedance realized the transformation from SICL to microstrip line with a characteristic impedance of $50 \Omega$. The microstrip line with a 


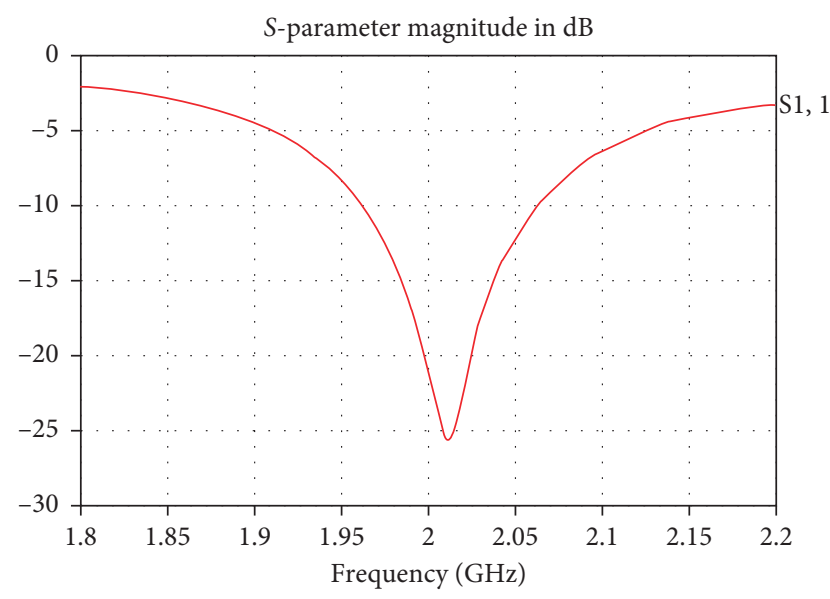

(a)

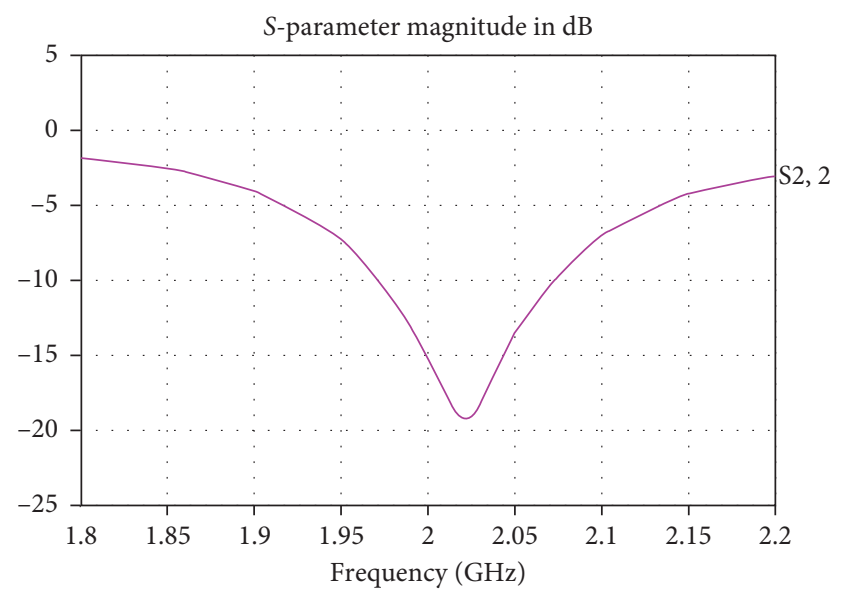

(b)

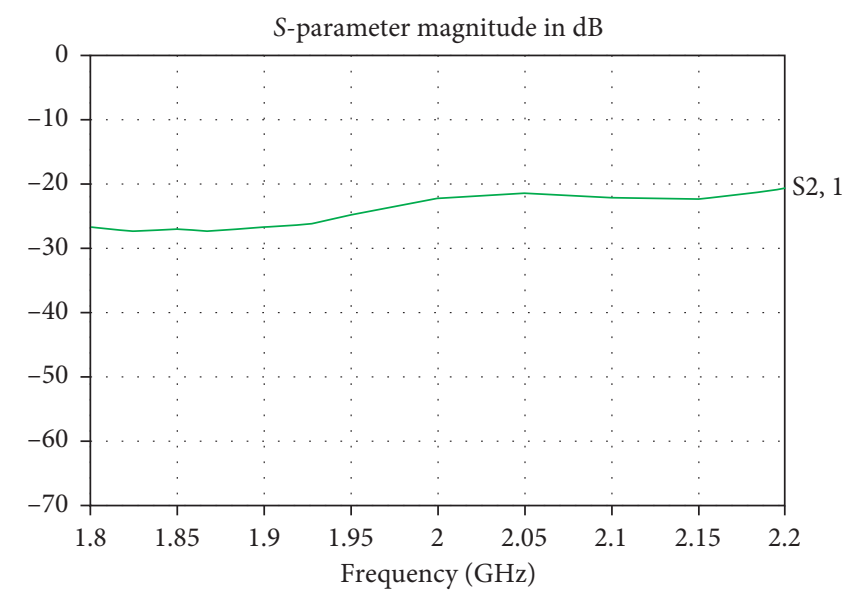

(c)

FIGURE 7: S-parameter simulation results of the dual-polarized antenna based on SICL. (a) The simulated return loss of polarization port 1. (b) The simulated return loss of polarization port 2. (c) The simulated isolation degree between two polarization ports.

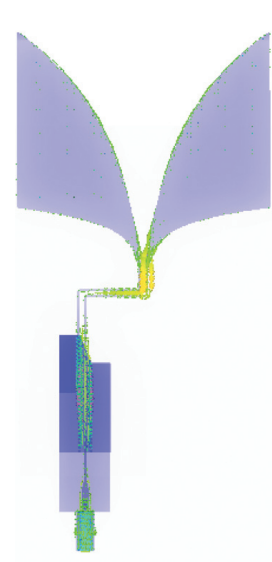

(a)

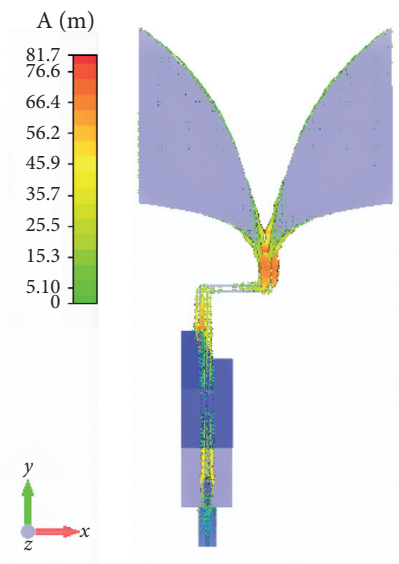

(b)

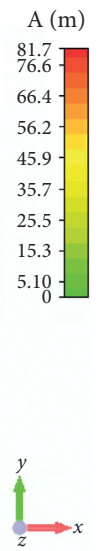

)

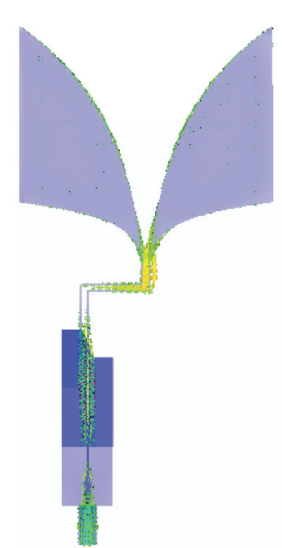

(c)
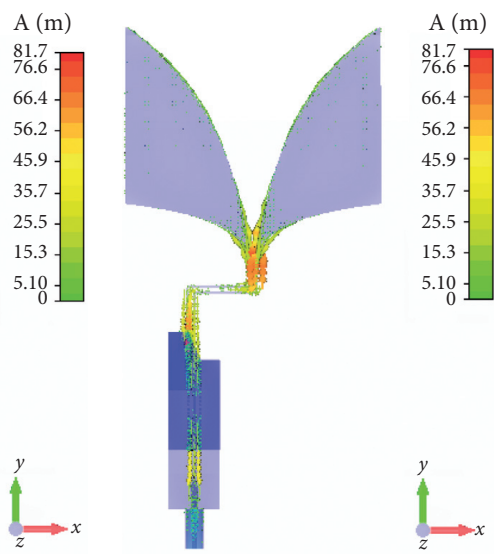

(d)

FIgURE 8: Current distributions on the dual-polarized antenna based on the SICL balun: (a) $t=0$, (b) $t=T / 4$, (c) $t=T / 2$, and (d) $t=3 T / 4$.

characteristic impedance of $50 \Omega$ was connected with the coaxial cable of the transmitter or the receiver. The SICL designed in this paper included two layers of substrates which had different thicknesses, and the thicknesses of the substrates on the bottom layer and the top layer were $h_{2}$ and $h_{1}$, respectively. In this section, $h_{2}$ was determined to be 


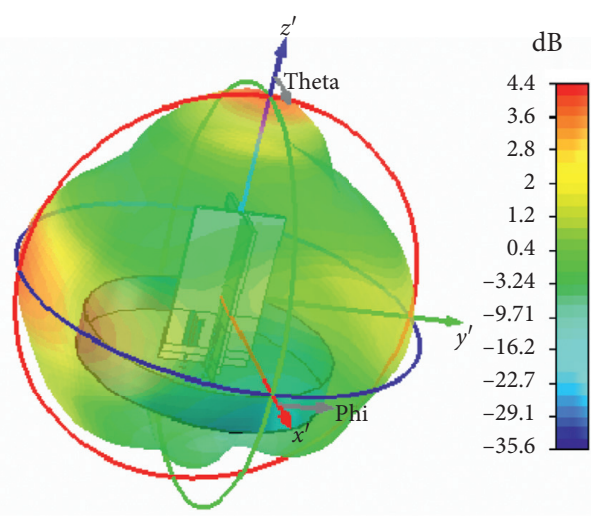

(a)

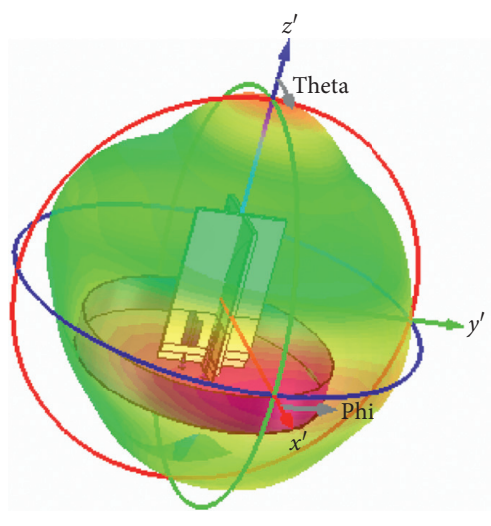

(c)

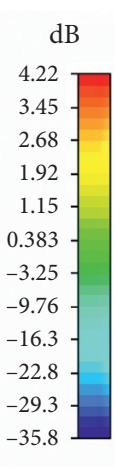

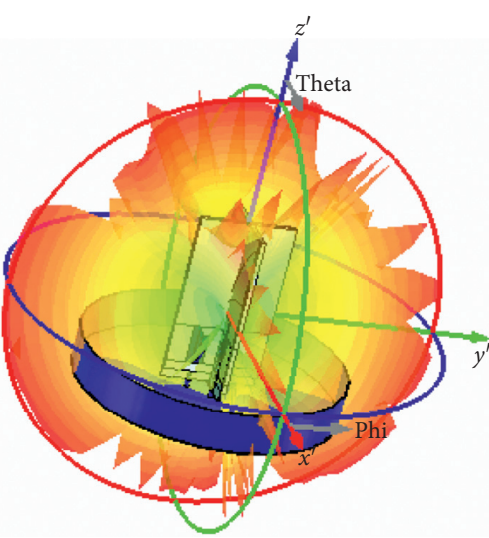

(b)

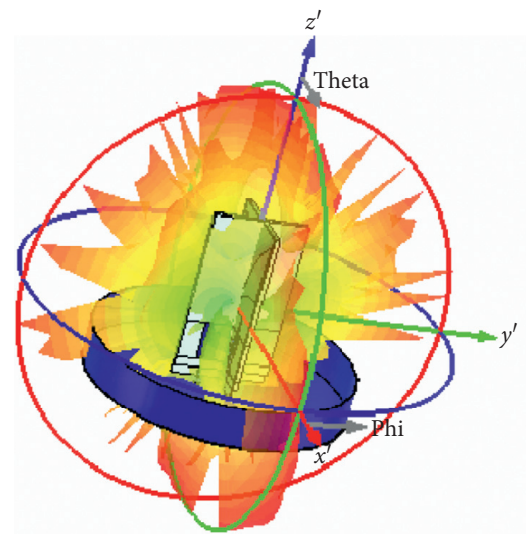

(d)
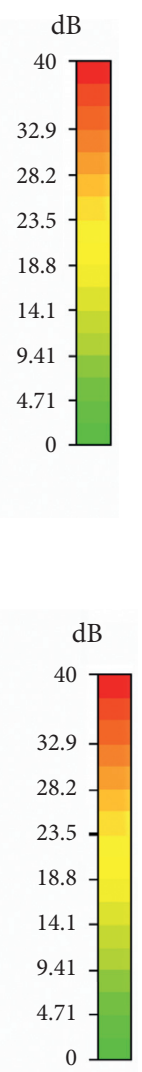

FIGURE 9: Three-dimension patterns of the dual-polarized antenna based on the SICL balun. (a) The gain of port 1 . (b) The AR of port 1. (c) The gain of port 2. (d) The AR of port 2 .

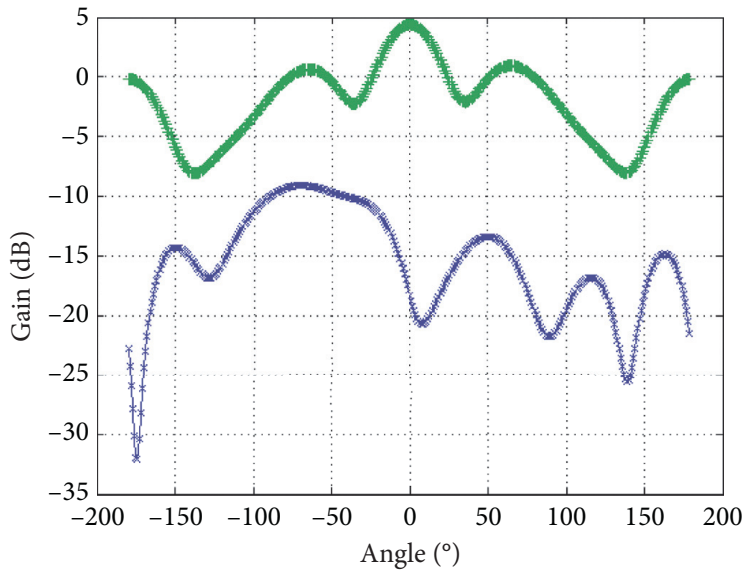

* Copolar at E plane

-+- Cross polar at E plane

(a)

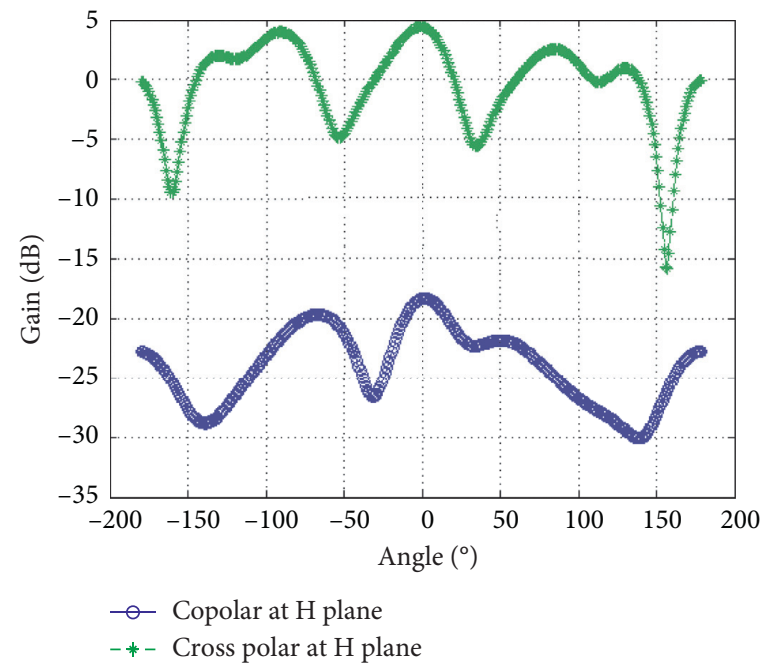

(b)

Figure 10: Continued. 


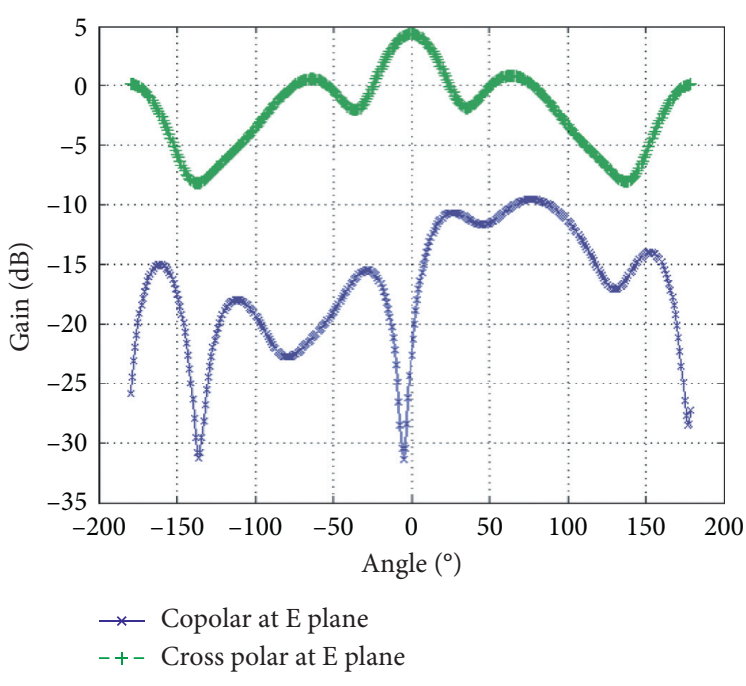

(c)

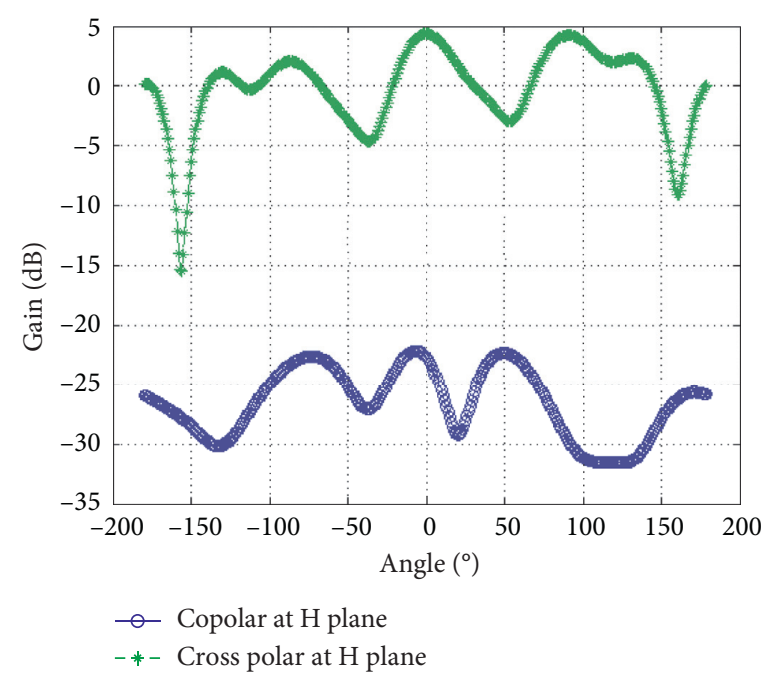

(d)

Figure 10: Simulated E and H plane patterns of the dual-polarized antenna: (a) patterns at the E plane for port 1, (b) patterns at the H plane for port 1, (c) patterns at the E plane for port 2, and (d) patterns at the $\mathrm{H}$ plane for port 2.

$1 \mathrm{~mm}$, and $h_{1}$ was changed to obtain the impedance matching and port isolation. Both two-layer substrates were selected to be FR-4. The diameter of conducting holes and distance between two adjacent holes are $r$ and $d$.

Figure 3 shows the circuit model of the SICL balun. The radiation impedance of the printed dipole antenna is $Z_{A}$, and the feeding line is CPS with the characteristic impedance of $Z_{02}$. The input microstrip line is an unbalanced structure, in which characteristic impedance is $Z_{01}$. The impedance matrix of the whole feeding balun is $[Z]$, and its normalized impedance matrix is $[\widetilde{Z}]$. The corresponding transition matrix of the whole feeding balun is $[A]$, and its normalized transition matrix is $[\widetilde{A}]$. According to the conversion formula between the network matrix, we can obtain the formula

$$
[\widetilde{A}]=\frac{1}{\widetilde{Z}_{21}}\left[\begin{array}{cc}
\widetilde{Z}_{11} & \operatorname{det}([\widetilde{Z}]) \\
1 & \widetilde{Z}_{22}
\end{array}\right],
$$

where $\operatorname{det}([\widetilde{Z}])=\widetilde{Z}_{11} \widetilde{Z}_{22}-\widetilde{Z}_{12} \widetilde{Z}_{21}$.

From the matrix $[\widetilde{A}]$, the four matrix elements can be expressed as

$$
\begin{aligned}
& A_{11}=\widetilde{A}_{11} \sqrt{\frac{Z_{01}}{Z_{02}}}, \\
& A_{12}=\widetilde{A}_{12} \sqrt{Z_{01} Z_{02}}, \\
& A_{21}=\frac{\widetilde{A}_{21}}{\sqrt{Z_{01} Z_{02}}}, \\
& A_{22}=\widetilde{A}_{22} \sqrt{\frac{Z_{02}}{Z_{01}}} .
\end{aligned}
$$

Then, the input impedance of the SICL balun can be expressed as

$$
Z_{\text {in }}=\frac{A_{11} Z_{A}+A_{12}}{A_{21} Z_{L}+A_{22}} .
$$

When the input port is in the matching state, $Z_{\text {in }}=Z_{0}=50 \Omega$. It can be seen that impedance matching can be realized by adjusting $Z_{A}$ and $[Z] . Z_{A}$ is determined by the structure and parameters of the antenna radiator. The impedance matrix of the SICL balun can be changed by adjusting the length $f_{1}$ of tapered slot SICL, the width $w$ of internal the conducting strip, and the distance $w_{s}$ between two column conducting holes.

The whole balun realizes the function of transformation from balance to unbalance and impedance matching from microstrip line to printed CPS. The antenna radiator is the terminal load of the CPS output port. The whole circuit system achieves good power transmission performance. The parameters of the whole balun are optimized by electromagnetic simulation. The obtained transmission performance curve of the designed balun in this paper is shown in Figure 4. It can be seen that the insertion loss is about $-1.89 \mathrm{~dB}$ at the central frequency point.

2.3. Structure of the Dual-Polarized Backed Cavity Dipole Antenna. Two polarized dipole radiators of the designed dual-polarized antenna fed by the tapered slot SICL balun were realized through the printed circuit board (PCB) in this paper. The designed dipoles of dual-polarized were exponentially tapered, which is like the Vivaldi antenna, whereas it is indeed a dual-polarized dipole antenna. For each polarization port, two arms of the dipole radiator are placed on the same side of the medium substrate, which are fed by CPS. The adopted feeding method can realize the impedance matching between the dipoles and the feeding line. In order to improve the feed efficiency, the SICL balun was designed, which realizes the transformation from microstrip line to 

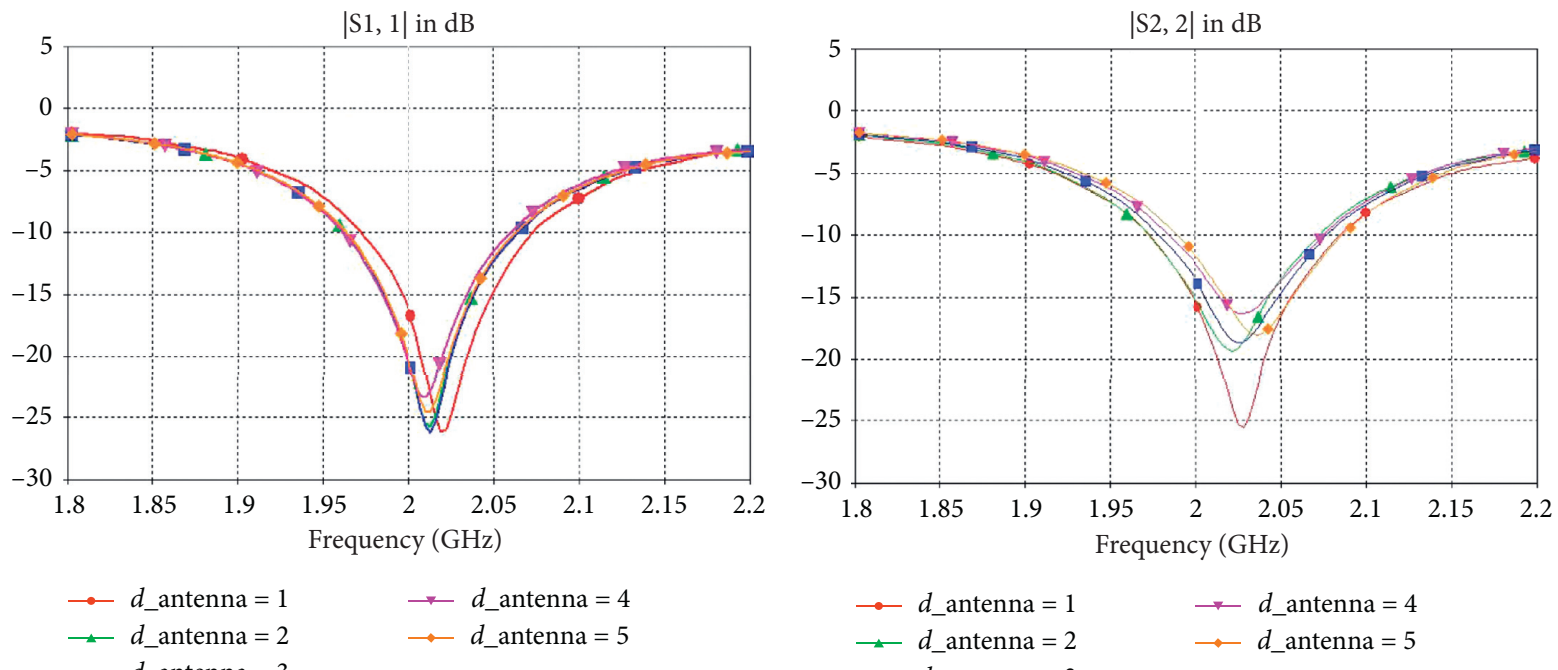

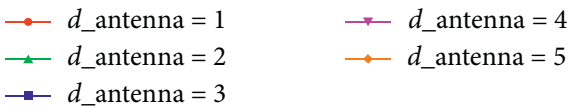

(a) (b)

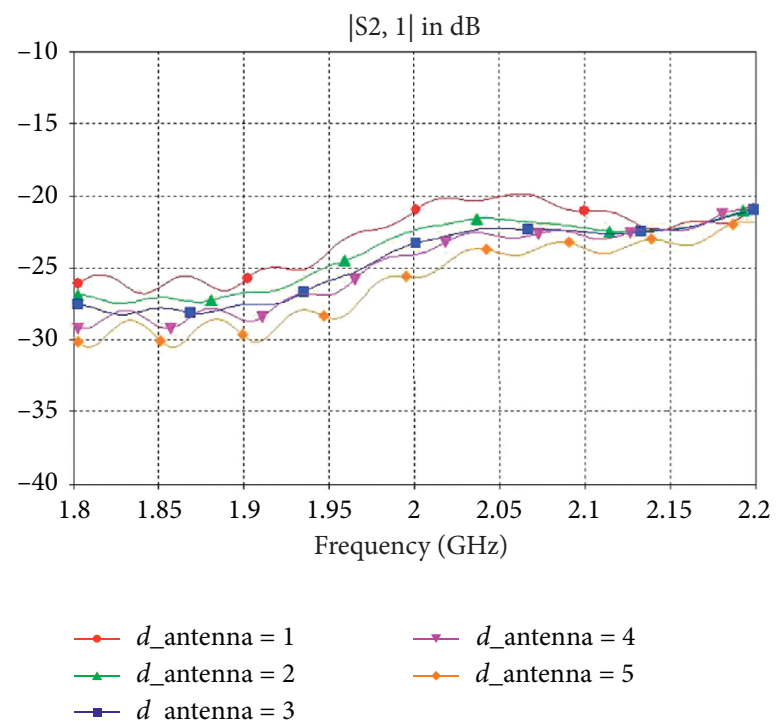

(c)

FiguRE 11: The effect curves of $d_{-}$antenna on antenna performances. (a) Effect on the return loss of port 1 with $d_{-}$antenna. (b) Effect on the return loss of port 2 with $d_{-}$antenna. (c) Effect on the isolation degree with $d_{-}$antenna.

CPS. The SICL balun was also designed to achieve the impedance matching from the input microstrip line to the coplanar dipole radiator. In the SICL balun, there is a transition section between the input microstrip line and the SICL. The whole structure schematic diagram of the designed dual-polarized antenna based on the SICL balun is shown in Figure 5.

In this paper, the exponentially tapered dipoles which can be seen called as Vivaldi-shaped dipoles, were designed. The designed structure diagram of the Vivaldi-shaped dipole antenna based on the SICL balun is shown in Figure 6 . According to the coordinate system in Figure 5, the equation of curve 1 can be written as

$$
x_{1}=a_{1} e^{r_{1} y}+d_{1} \text {, }
$$

where both $a_{1}$ and $d_{1}$ are constants, which are used to control the size of the dipole.

Also, the equation of curve 1 can be written as

$$
x_{2}=a_{2} e^{r_{1} y}+d_{2},
$$

where both $a_{2}$ and $d_{2}$ are constants, which are used to control the bottom shape of the dipole.

In the procedure of the fabrication of the dual-polarized printed dipole antenna, the two polarization radiation parts are orthogonally mounted, so occlusion phenomenon appears, which causes the low isolation between two polarization ports. In this paper, the transmission lines were bended, and the two orthogonal dipoles were separated at the vertical direction, so the two polarization radiators did not cross. According to this method, two substrates of the 

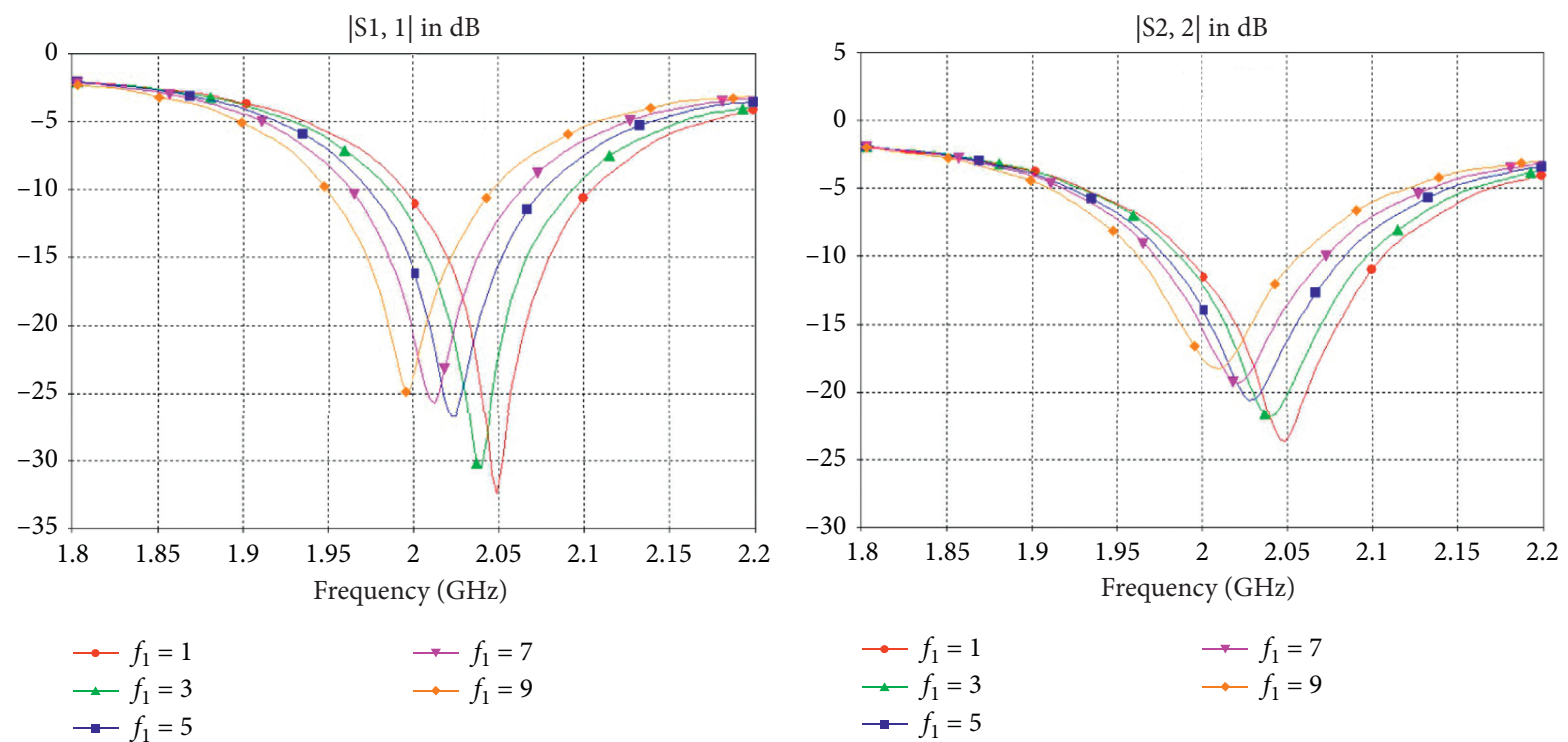

(a)

(b)

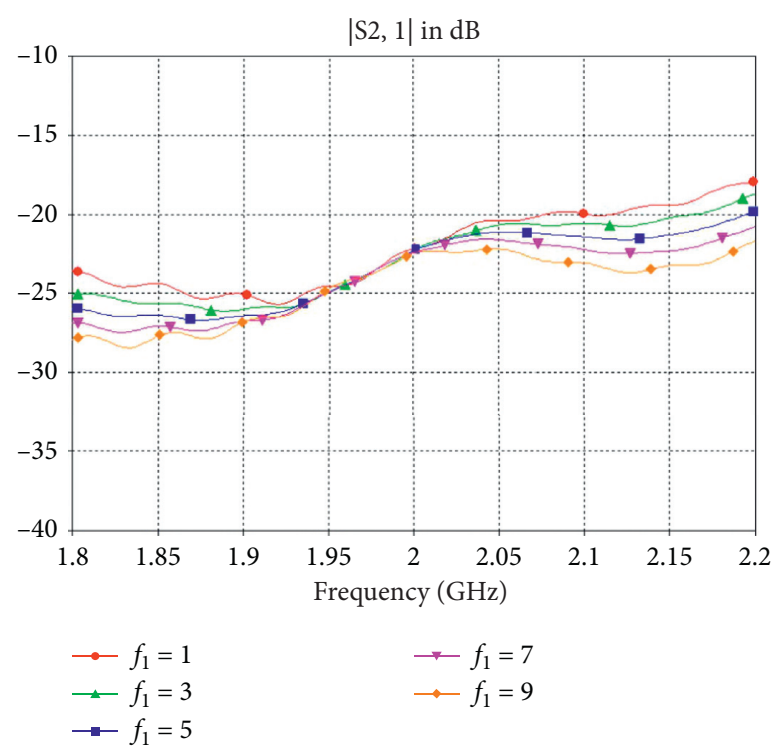

(c)

FiguRE 12: The effect curves of $f_{1}$ on antenna performances. (a) Effect on the return loss of port 1 with $f_{1}$. (b) Effect on the return loss of port 2 with $f_{1}$. (c) Effect on the isolation degree with $f_{1}$.

dual-polarized antenna can be mounted and fixed directly, and jumper work was avoided, which is beneficial to the practical engineering. The value of height difference between two SICL baluns is defined as $d_{-}$antenna.

\section{Performance Analysis and Optimization of the Dual-Polarized Antenna Fed by the Tapered Slot SICL Balun}

According to performance requirements of impedance matching, isolation degree, and patterns in engineering, the full-wave electromagnetic simulation technique was used to simulate and optimize the dual-polarized printed dipole antenna based on the SICL balun. A set of parameter values that meet the requirements are $f_{1}=7 \mathrm{~mm}, f_{3}=15 \mathrm{~mm}$, $c_{1}=10 \mathrm{~mm}, g_{1}=15 \mathrm{~mm}, g_{2}=6 \mathrm{~mm}, w_{s}=3 \mathrm{~mm}, w=0.6 \mathrm{~mm}$, $h_{1}=3.5 \mathrm{~mm}, h_{2}=1 \mathrm{~mm}$, and $w \_$edge_ $1=5 \mathrm{~mm}$. Figure 7 shows the simulated $S$-parameter results. At the operational frequency of $2 \mathrm{GHz}$, the return losses of two ports are lower than $-10 \mathrm{~dB}$, and the isolation degree is larger than $22 \mathrm{~dB}$.

The current distributions on the patches are shown in Figure 8. It can be seen that the proposed SICL balun can transform the quasi-TEM mode of the microstrip line to the TEM mode of CPS. With the period of $T$ at $2 \mathrm{GHz}$, the currents on the dipole focus on the edges of dipole arms, which lead to linearly polarized radiation fields, and the effective radiation mode is achieved. 


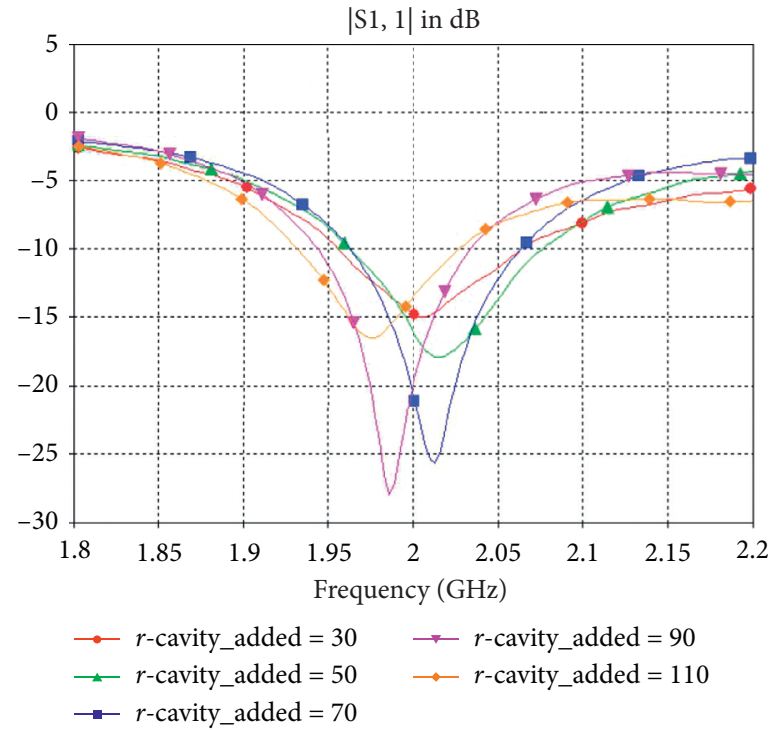

(a)

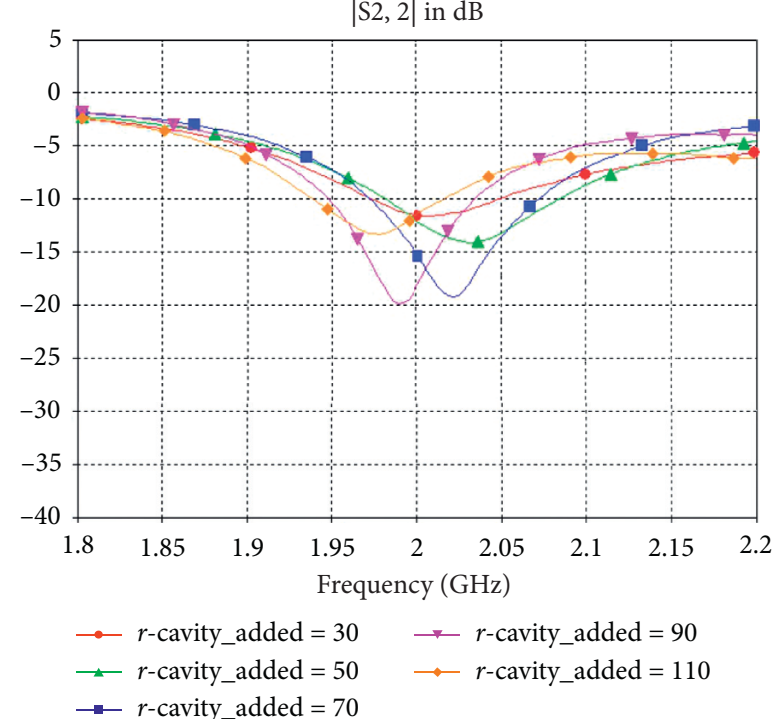

(b)

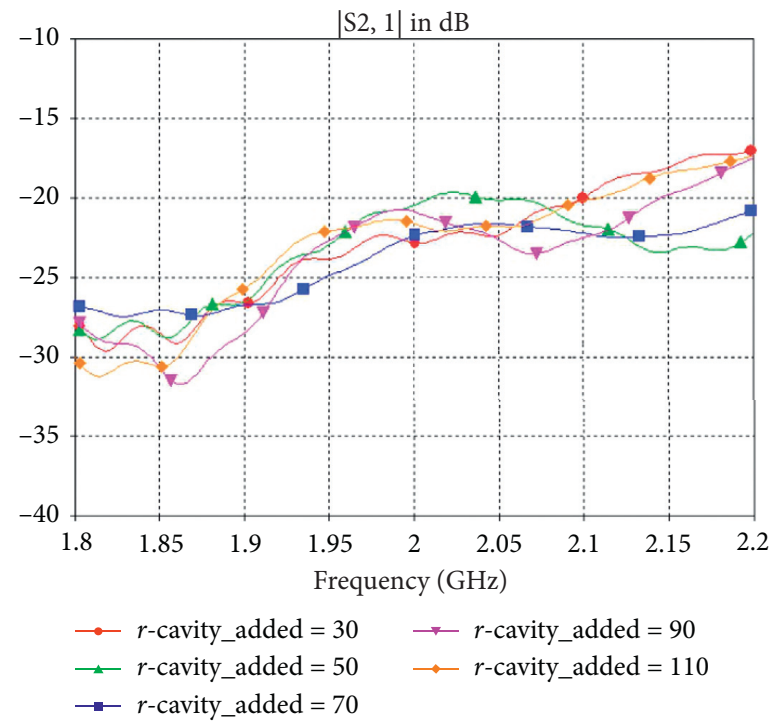

(c)

FiguRE 13: The effect curves of $r_{-}$cavity_added on antenna performances. (a) Effect on the return loss of port 1 with $r_{-}$cavity_added.

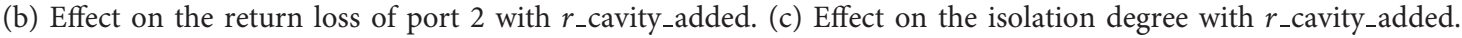

Figure 9 shows the three-dimension radiation patterns of two ports at the working frequency, and for each port, the gain pattern and axial ratio pattern are provided, respectively. According to the simulated results, the axial ratios of two ports are higher than $30 \mathrm{~dB}$, which indicates the low cross polarization levels are obtained. The simulated gains of two ports are about $4.4 \mathrm{dBi}$ and $4.2 \mathrm{dBi}$, respectively; moreover, the approximate symmetric patterns for two ports are observed.

The simulated $\mathrm{E}$ and $\mathrm{H}$ plane patterns of two ports at working frequency for the dual-polarized antenna are shown in Figure 10. According to Figure 9, for port 1, the half power beam widths at the $\mathrm{E}$ plane and the $\mathrm{H}$ plane are about $40.5^{\circ}$ and $40.6^{\circ}$, respectively. For port 2 , the half power beam widths at the E plane and the $\mathrm{H}$ plane are about $40.4^{\circ}$ and $41.4^{\circ}$, respectively. It is obvious that two ports have achieved almost symmetric radiation patterns.

During the antenna optimization, the effects of $d_{-}$antenna, $f_{1}$, and the radius added value $r_{-}$cavity_addedof cavity on the return losses and isolation degree between ports were simulated. Simulated variation curves of the return loss and isolation degree with $d_{-}$antenna are shown in

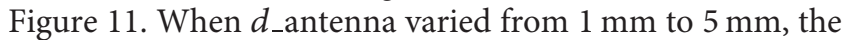
return loss changes little, yet the isolation degree becomes larger obviously. What is more, when $d_{-}$antenna is $2 \mathrm{~mm}$, the return loss is less than $-10 \mathrm{~dB}$ and the isolation degree is higher than $22 \mathrm{~dB}$, which can satisfy the requirements in engineering.

Simulated variation curves of the return loss and isolation degree with $f_{1}$ are shown in Figure 12. When $f_{1}$ varied from 


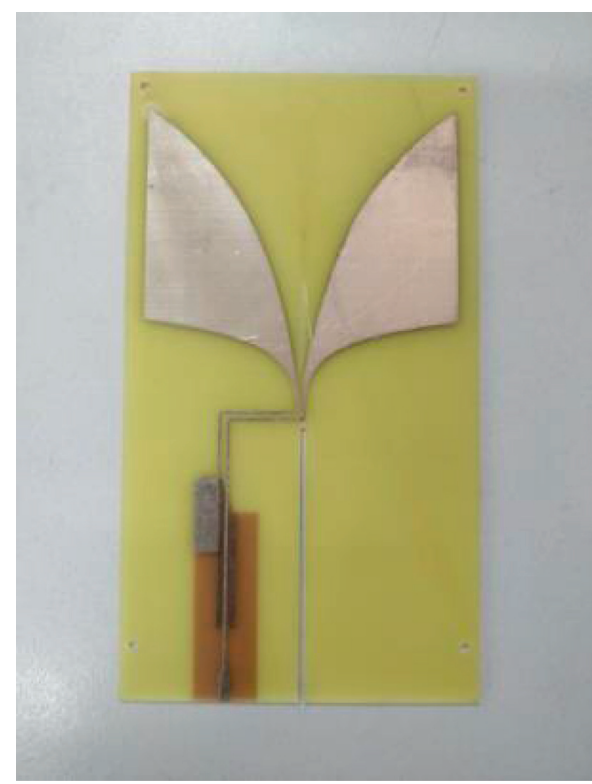

(a)

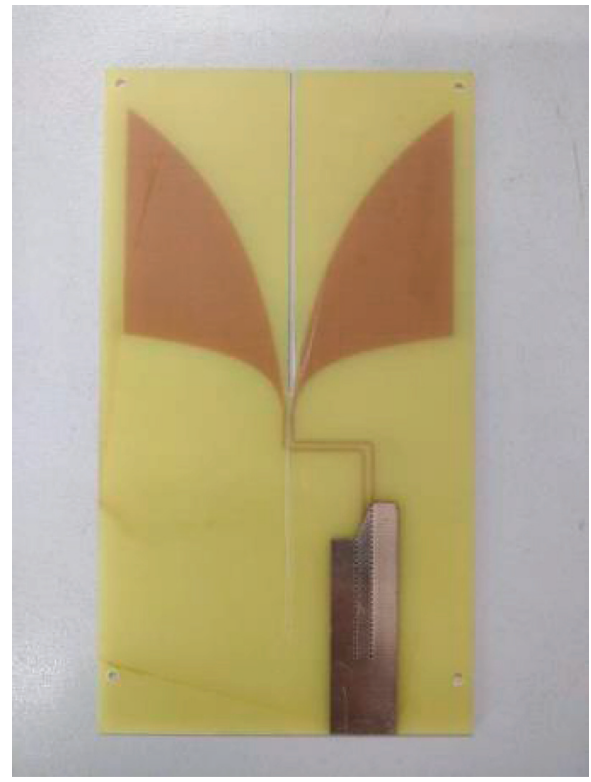

(c)

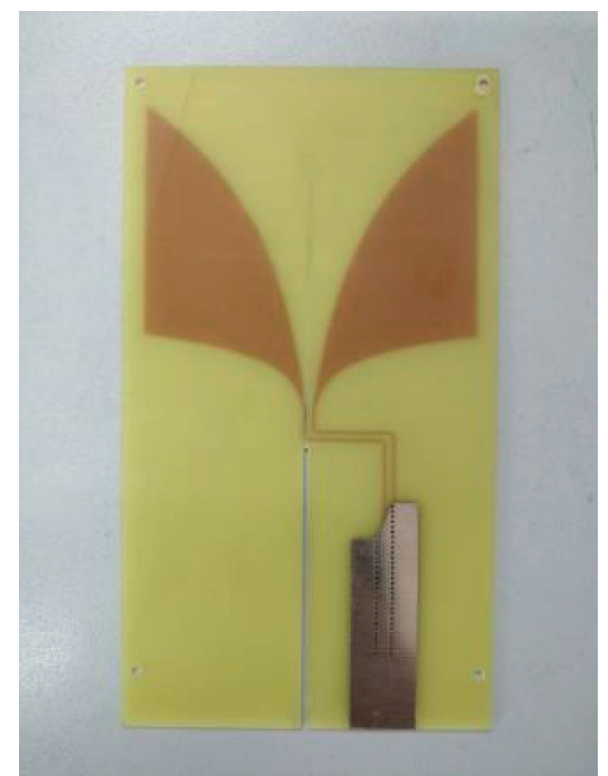

(b)

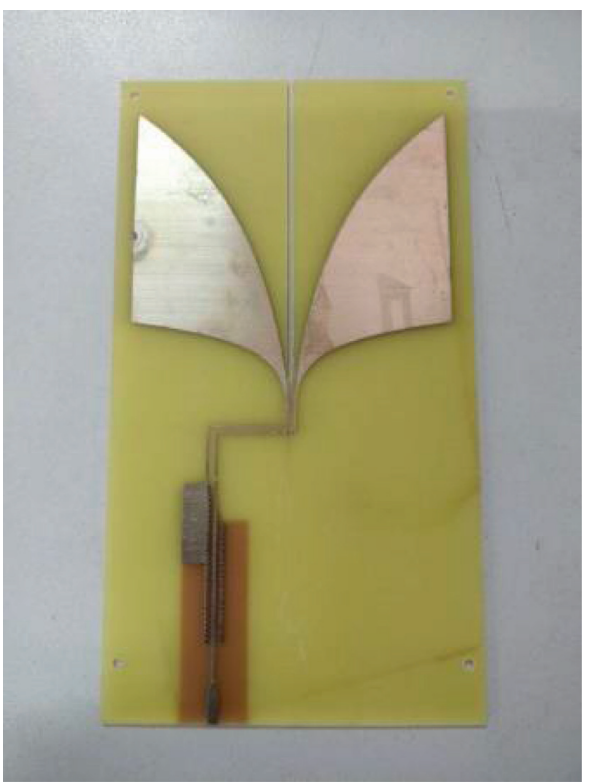

(d)

FIGURE 14: The photo of the dual-polarized antenna prototype. (a) The front view of PCB for port 1. (b) The back view of PCB for port 1. (c) The front view of PCB for port 2. (d) The back view of PCB for port 2.

$1 \mathrm{~mm}$ to $9 \mathrm{~mm}$, the resonant frequency moves to lower frequency band for two ports, whereas the isolation degree almost unchanged. It can be seen that the return loss is less than $-10 \mathrm{~dB}$ and the isolation degree higher than $22 \mathrm{~dB}$ when $f_{1}$ is $7 \mathrm{~mm}$.

Simulated variation curves of the return loss and isolation degree with $r_{-}$cavity_added are shown in Figure 13. When $r_{-}$cavity_added varied from $30 \mathrm{~mm}$ to $110 \mathrm{~mm}$, $r_{-}$cavity_added mainly affects the impedance matching degree, while has slight influence on the resonant frequency. The isolation degree did not change remarkably with $r_{-}$cavity_added.

The fabrication errors of the antenna designed in this paper mainly come from the assembly errors between two bipolar circuit boards and the installation errors of the cylindrical metal cavity. The fabrication errors of the circuit boards are very small and can be neglected. The error simulation is carried out by using full-wave electromagnetic simulation technology, and the distance between the bottom of the cavity and the printed circuit board is studied. The simulation results show that the VSWR and the isolation of polarization ports at the input end almost have no obvious variations within the small assembly error range of less than $5 \mathrm{~mm}$, and the radiation pattern of the antenna has little variation except that the gain is changed about $0.7 \mathrm{~dB}$ compared with the designed value. Therefore, the difference between the simulation and calculation results of the 


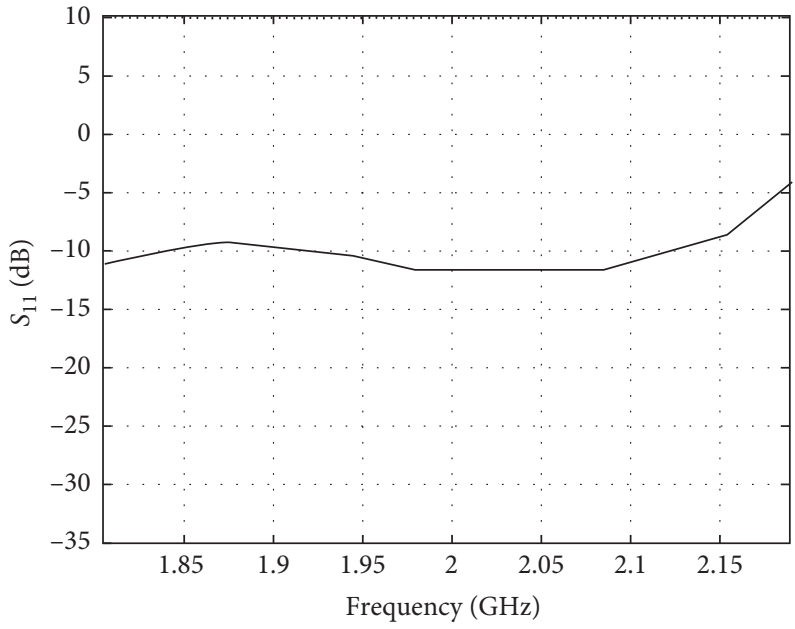

(a)

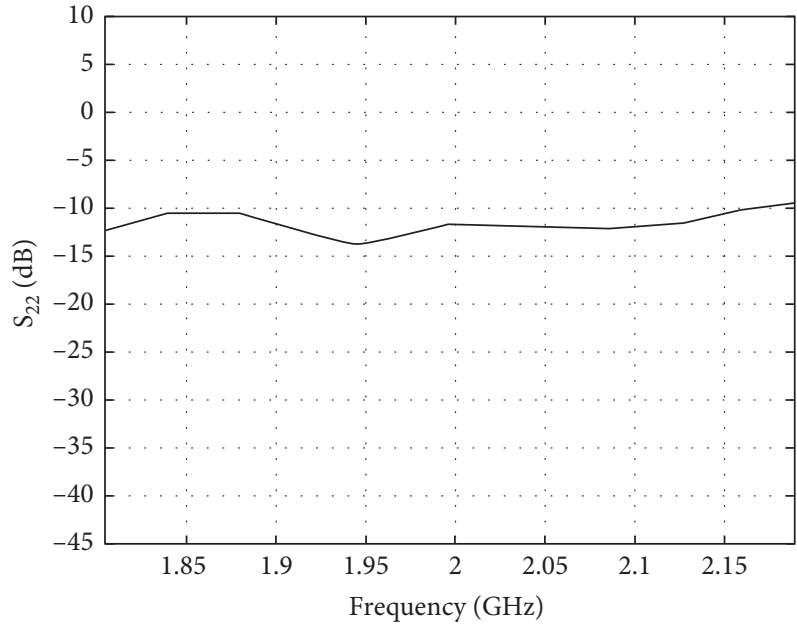

(b)

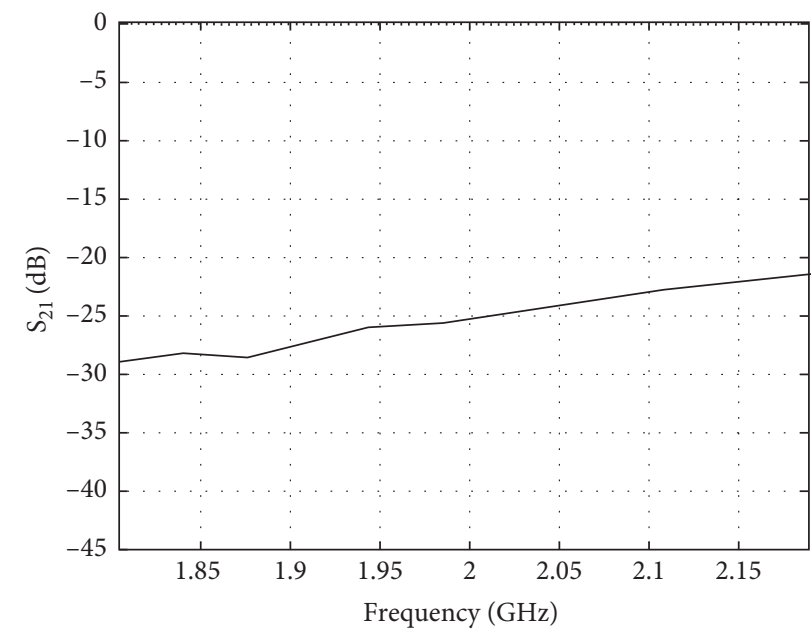

(c)

FIgURE 15: Tested circuit characteristics of the dual-polarized antenna. (a) The measured return loss of port 1. (b) The measured return loss of port 2. (c) The measured isolation degree between two ports.

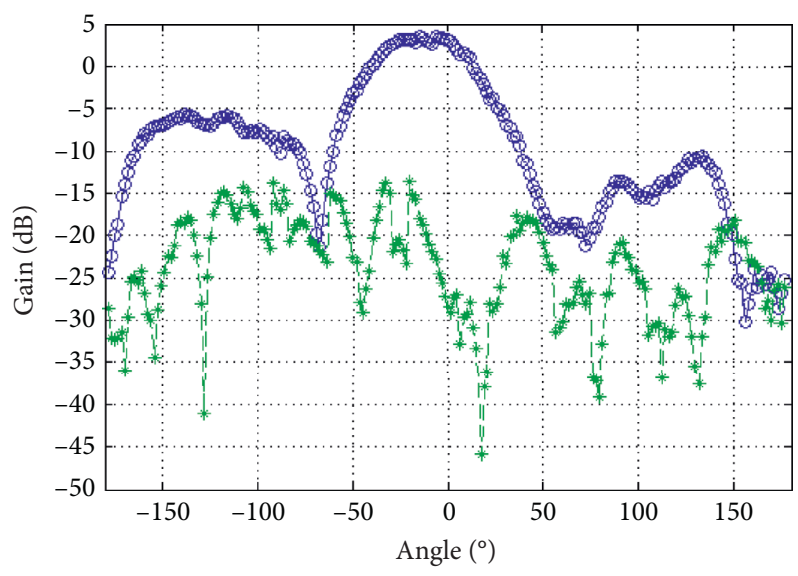

- Copolar

$-*$ - Cross polar

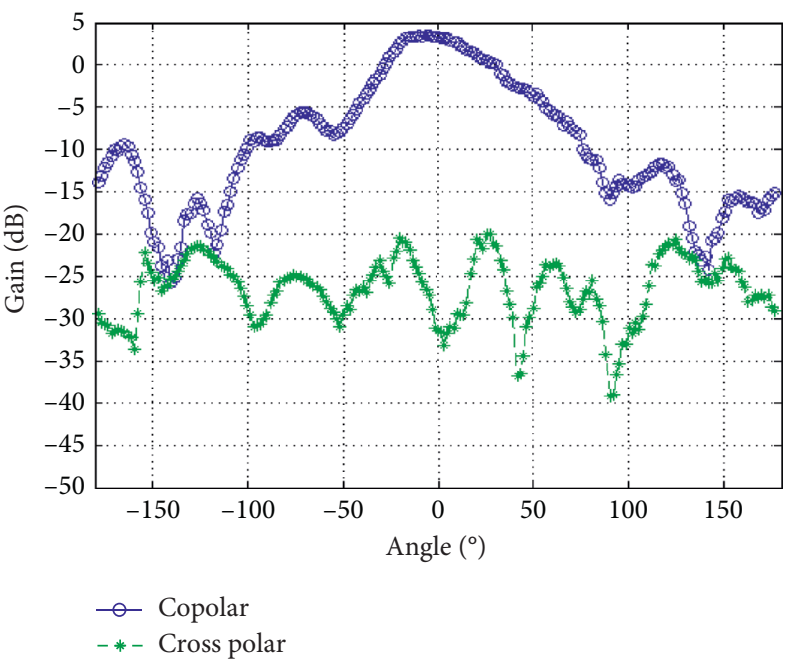

(b)

FIgURE 16: Measured patterns of polarization port 1. (a) The pattern at the E plane. (b) The pattern at the H plane. 


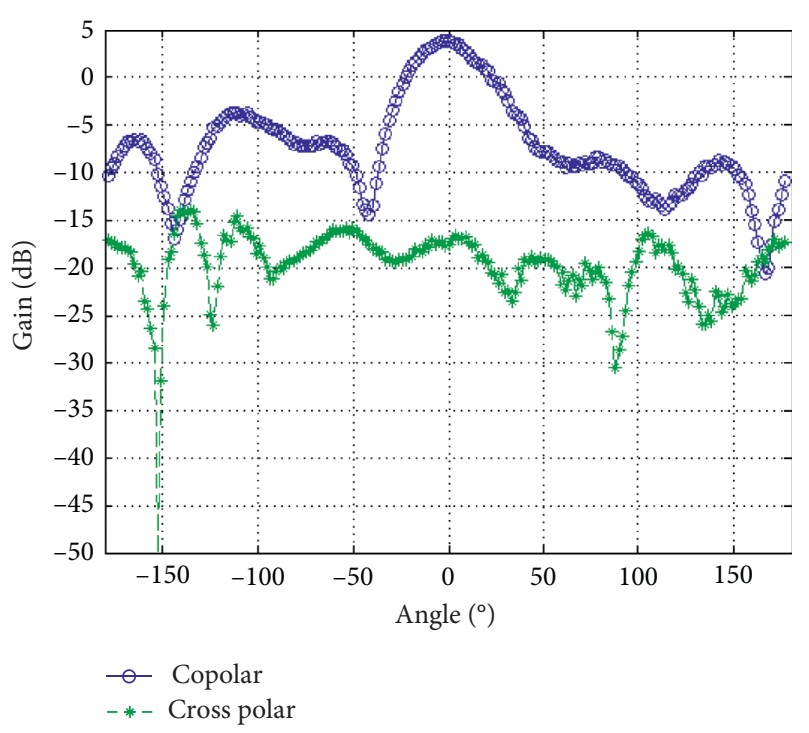

(a)

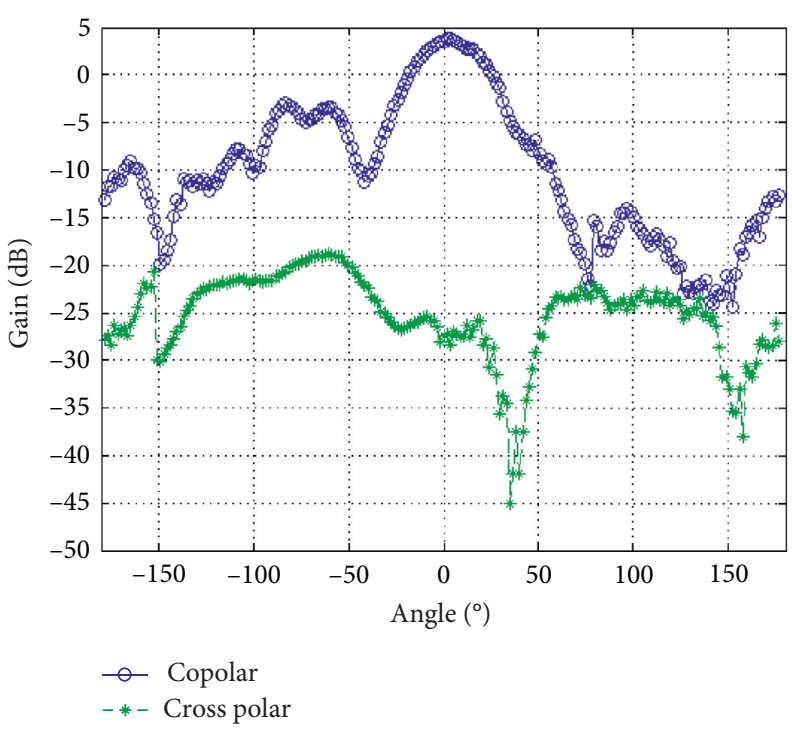

(b)

FIgURE 17: Measured patterns of polarization port 2. (a) The pattern at the E plane. (b) The pattern at the H plane.

antenna designed in this paper mainly comes from the test error. Due to the limitation of laboratory experimental conditions, the test error of the antenna is slightly larger. However, the test results are basically consistent with the simulation results, which verify the design scheme.

\section{Experiment Results of the Antenna Prototype}

According to the structure and size, the designed dualpolarized dipole antenna fed by the SICL balun was fabricated. The PCB photo of the antenna prototype is shown in Figure 14 . The simulated return losses and isolation degree between two ports are shown in Figures 15(a), 11(b), and 11(c), respectively. At the working frequency, the return losses of two ports are lower than $-10 \mathrm{~dB}$, and the measured return losses are almost in agreement with the simulated results. The measured isolation degree is higher than $25 \mathrm{~dB}$ at the working frequency, which is better than the simulated result.

The radiation patterns were measured in the anechoic room, and the measured patterns of two ports at the working frequency are shown in Figures 16 and 17, respectively. For each port, the patterns at both $\mathrm{E}$ plane and $\mathrm{H}$ plane are provided, respectively. It can be seen that the radiation patterns are formed effectively. The measured gain of port 1 is about $0.9 \mathrm{~dB}$ lower than the simulated ones, and the measured cross polarization level of port 1 is about $-25 \mathrm{~dB}$. The measured gain of port 2 is about $0.6 \mathrm{~dB}$ lower than that of simulated ones, and the measured cross polarization level of port 2 is about $-28 \mathrm{~dB}$. For both port 1 and port 2 , the beam widths are close to the simulated results. The measured performances are worse than the simulated results owing to the errors caused by fabrication and measurement.

\section{Conclusion}

This paper proposed a tapered slot SICL balun and designed a dual-polarized printed dipole antenna fed by the proposed SICL balun. The analysis method of the SICL balun was depicted. For the designed dual-polarized antenna, a cylindrical metal backed cavity is used to improve the $\mathrm{F} / \mathrm{B}$ of radiation patterns. The designed backed cavity dual-polarized printed dipole antenna is excited by bended coplanar strip lines which can avoid the occlusion of two ports and improve the isolation degree between two ports. The SICL feeder realized the balanced-to-unbalanced transformation from the dipoles to the microstrip line, and the impedance transformation was also obtained. The simulation and experimental results verify the scheme of the SICL balun and the dual-polarized antenna. The researched dual-polarized antenna fed by the tapered slot SICL balun can be used in airborne radar.

\section{Data Availability}

The data supporting the conclusions of the study are plotted in the picture of this paper. Researchers can obtain data from this paper.

\section{Conflicts of Interest}

The authors declare that they have no conflicts of interest.

\section{Acknowledgments}

This work was supported by the Foundation of Hebei Educational Committee (QN2018044), the Natural Science Foundation of Shandong Province (no. ZR2019MA055), open project of the State Key Laboratory of Surface Physics 
and Department of Physics (no. KF2019_05), and the Key Laboratory of Micro and Nano-Photonic Structures (Ministry of Education).

\section{References}

[1] T. Chaloun, V. Ziegler, and W. Menzel, "Design of a dualpolarized stacked patch antenna for wide-angle scanning reflectarrays," IEEE Transactions on Antennas and Propagation, vol. 64, no. 8, pp. 3380-3390, 2016.

[2] M. Sporer, R. Weigel, and A. Koelpin, "A $24 \mathrm{GHz}$ dual-polarized and robust dielectric rod antenna," IEEE Transactions on Antennas and Propagation, vol. 65, no. 12, pp. 6952-6959, 2017.

[3] L. Schulwitz and A. Mortazawi, "Millimeter-wave dual polarized L-shaped horn antenna for wide-angle phased arrays," IEEE Transactions on Antennas and Propagation, vol. 54, no. 9, pp. 2663-2668, 2006.

[4] R. V. S. R. Krishna and R. Kumar, "A dual-polarized squarering slot antenna for UWB, imaging, and radar applications," IEEE Antennas and Wireless Propagation Letters, vol. 15, pp. 195-198, 2016.

[5] S. Jamilan, M. A. Antoniades, J. Nourinia, and M. N. Azarmanesh, "A directivity-band-dependent tripleband and wideband dual-polarized monopole antenna loaded with a via-free CRLH unit cell," IEEE Antennas and Wireless Propagation Letters, vol. 14, pp. 855-858, 2015.

[6] O. M. Haraz, A.-R. Sebak, and T. A. Denidni, "Dual-polarised dielectric-loaded monopole antenna for wideband communication applications," IET Microwaves, Antennas \& Propagation, vol. 6, no. 6, pp. 663-669, 2012.

[7] A. R. Weily and N. Nikolic, "Dual-polarized planar feed for low-profile hemispherical luneburg lens antennas," IEEE Transactions on Antennas and Propagation, vol. 60, no. 1, pp. 402-407, 2012.

[8] B. Q. Wu and K. M. Luk, "A broadband dual-polarized magneto-electric dipole antenna with simple feeds," IEEE Antennas and Wireless Propagation Letters, vol. 8, pp. 60-63, 2009.

[9] Y. Shao, X.-C. Li, L.-S. Wu, and J.-F. Mao, "A wideband millimeter-wave substrate integrated coaxial line array for high-speed data transmission," IEEE Transactions on Microwave Theory and Techniques, vol. 65, no. 8, pp. 2789-2800, 2017.

[10] T. Y. Yang, Y. W. Hong, and Y. Zhang, "An SICL-excited wideband circularly polarized cavity-backed patch antenna for IEEE 802.11aj (45 GHz) applications," IEEE Antennas and Wireless Propagation Letters, vol. 15, pp. 1265-1268, 2016.

[11] Q. Wu, H. Wang, C. Yu, X. Zhang, and W. Hong, "L/S-band dual-circularly polarized antenna fed by 3 -dB coupler," IEEE Antennas and Wireless Propagation Letters, vol. 14, pp. 426429, 2015.

[12] B. Liu, R. Zhao, Y. Ma et al., "A $45^{\circ}$ linearly polarized slot array antenna with substrate integrated coaxial line technique," IEEE Antennas and Wireless Propagation Letters, vol. 17, no. 2, pp. 339-342, 2018.

[13] K. Xing, B. Liu, Z. Guo, X. Wei, R. Zhao, and Y. Ma, "Backlobe and sidelobe suppression of a $Q$-band patch antenna array by using substrate integrated coaxial line feeding technique," IEEE Antennas and Wireless Propagation Letters, vol. 16, pp. 3043-3046, 2017.

[14] Z.-W. Miao and Z.-C. Hao, "A wideband reflectarray antenna using substrate integrated coaxial true-time delay lines for
QLink-Pan applications," IEEE Antennas and Wireless Propagation Letters, vol. 16, pp. 2582-2585, 2017.

[15] F. Zhu, W. Hong, J.-X. Chen, and K. Wu, "Ultra-wideband single and dual baluns based on substrate integrated coaxial line technology," IEEE Transactions on Microwave Theory and Techniques, vol. 60, no. 10, pp. 3062-3070, 2012.

[16] A. Belenguer, A. L. Borja, H. Esteban, and V. E. Boria, "Highperformance coplanar waveguide to empty substrate integrated coaxial line transition," IEEE Transactions on Microwave Theory and Techniques, vol. 63, no. 12, pp. 4027-4034, 2015.

[17] F. Quiles, Á. Belenguer, J. A. Martínez, V. Nova, H. Esteban, and V. Boria, "Compact microstrip to empty substrateintegrated coaxial line transition," IEEE Microwave and Wireless Components Letters, vol. 28, no. 12, pp. 1080-1082, 2018.

[18] M. Cariou, P. Benjamin, C. Quendo et al., "Compact X-band filter based on substrate integrated coaxial line stubs using advanced multilayer PCB technology," IEEE Transactions on Microwave Theory and Techniques, vol. 65, no. 2, pp. 496-503, 2017.

[19] A. L. Borja, A. Belenguer, H. Esteban, and V. E. Boria, “Design and performance of a high- $Q$ narrow bandwidth bandpass filter in empty substrate integrated coaxial line at $K_{u}$-band," IEEE Microwave and Wireless Components Letters, vol. 27, no. 11, pp. 977-979, 2017.

[20] P. Chu, W. Hong, L. Dai et al., "Wide stopband bandpass filter implemented with spur stepped impedance resonator and substrate integrated coaxial line technology," IEEE Microwave and Wireless Components Letters, vol. 24, no. 4, pp. 218-220, 2014. 